\title{
Chapter 14 \\ Cinema and the "City of the Mind": \\ Using Motion Pictures to Explore \\ Human-Environment Transactions \\ in Planning Education
}

\author{
Michael Dudley
}

\subsection{Introduction}

The use of film analysis in teaching has become popular in recent years, especially in theology (see Kozlovic, 2005). It has taken on new importance because "film offers students an opportunity to connect the theoretical discourses we engage in classes to a range of social issues represented through the lens of Hollywood movies" (Giroux, 2001, p. 589).

This chapter examines the pedagogical use of film in planning education, specifically as it relates to the teaching of environmental psychology. The intersections between film, theory, and pedagogy are important because film is herein invested with the power to represent - and more importantly interpret and challenge - our understandings of human-environment transactions. I further suggest that planning students may be undereducated in the nature of these transactions and that the medium of the motion picture - combined with the neglected body of theory represented by environmental psychology - offers an excellent synthesis to address this need.

Planning as a field of study attracts students from across a wide range of disciplines, which lends it a certain intellectual diversity and hence resiliency. However beneficial, this interdisciplinarity often means planning theory instructors must assist students who lack a basic grounding in a number of theoretical areas, such as urban sociology and theories of urban morphological change.

Another major body of theory with which many planning students may be unfamiliar is that relating to human-environment transactions. Known variously as Environmental Psychology, Architectural Psychology, or Environment and Behavior Research (EBR $\left.{ }^{1}\right)$, theories and research concerning human spatial behavior have been evolving and maturing for more than 40 years and are highly germane to land-use planning as they relate to multiple levels of social and spatial scales and organization.

\footnotetext{
M. Dudley $(\bowtie)$

Institute of Urban Studies, University of Winnipeg, Winnipeg, MB, Canada

e-mail: m.dudley@uwinnipeg.ca
} 
Yet, the literature shows that EBR approaches are rarely taken into account in planning research and practice (Manzo \& Perkins, 2006) and are also a neglected body of theory in the academy (White \& Mayo, 2005). Apart from classic readings such as those of Lynch (1960) or Whyte (1988), little emphasis is paid to EBR in planning programs. Moreover, the leading organization of researchers in this field, the Environmental Design Research Association (EDRA), attracts few urban planners to its conferences (Sandercock \& Sarkissian, personal communication).

In spite of this relative lack of exposure to EBR theory, I find that planning students routinely find themselves either involved in or proposing for their graduate work, studies that concern how environments affect users; how to design urban environments that better meet psychological needs; how to promote more sustainable behavior in the built environment; or how behavior can affect environments. All of these themes fall within the purview of EBR. However, owing to a lack of attention in the curriculum to EBR, students may lack the necessary understanding and theoretical vocabulary with which to undertake such research.

The general premise of this chapter is that a greater emphasis should be placed on EBR in planning curricula. Its primary purpose, however, is to offer one possible means with which to do this: through the use of popular film as a pedagogical tool.

This chapter reports on the use of popular film as a medium to impart EBR theory in a classroom setting. It sets out the rationale for this approach, focusing on hermeneutic analysis as a pedagogic technique. Then it will illustrate these potentialities through hermeneutic film readings based on my experiences using film in teaching, incorporating both my analyses and those of my students.

The method I will follow is therefore not only interdisciplinary and integrative but collaborative. The interpretations I developed as an instructor to initially select the films and theoretical readings for the course will be augmented and elaborated upon in Section 14.6 below by students' insights, which shall be indicated with indented italics. My own reflections served as a foundation for theorizing on the part of my students. As Giroux (2001, p. 594) points out from his own teaching experiences, "my analyses of films are necessarily partial, incomplete and open to revision and contestation. Rather than closing down student participation, my own interpretations are meant to be strategic and positional."

The chapter will show how, through the use of film, the theoretical domains in question may be synthesized and taught. It will set out the practical, pedagogical, and theoretical bases for the use of film in a planning context, showing how motion pictures can present profound - and potentially radicalizing - insights into the human spatial experience.

\subsection{Background}

Between 2002 and 2008, I taught EBR in the context of a required undergraduate theory course in Environmental Design in the Faculty of Architecture at the University of Manitoba. Under the designation Theory of Design 3, the course follows upon two previous theory courses in general formal design concepts. 
In their final year of the undergraduate program, Environmental Design students can elect to focus on architecture, landscape architecture, interiors, or city planning. If they apply, city planning ED students are then often seen as strong candidates for the graduate program in city planning.

It was apparent during my first offering of Theory 3 that the course content would prove challenging to teach. Social science theory is a dramatic departure for most of the design students, many of whom have yet to write a major theory paper. Also, traditional outcome measures for social sciences education (i.e., exams) proved quite ineffective. My students informed me that, as visual thinkers, they were not interested in memorizing and repeating back facts and concepts.

In 2003, I added a film analysis to the curriculum as a seminar presentation, with no written submission required. I matched a selection of popular films with what I felt were appropriate readings and the students were asked to identify the concepts from the literature in the films.

The results were, I thought, very positive: the students were engaged in the assignment and appeared to enjoy conducting and attending the seminar much more than had been the case in earlier classes, when the seminar was concerned solely with the presentation of readings.

Based on this early success, in subsequent years I expanded the assignment to become the core of the course: in addition to a site investigation and the keeping of a theory journal, the students were tasked with not just presenting their findings on the film analysis, but to then submit their report as their group's final theory paper. The film analysis assignment appears to be an effective combination for the Environmental Design students, as it appeals to their visual learning orientations and allows them to assimilate and apply EBR theory in creative ways.

As stated, some of these students go on to the graduate program in city planning. In general, though, very few planning students at the University of Manitoba are acquainted with this body of theory.

The shortcoming this educational gap represents in planning education has become apparent to me for several years. Since 2001, I have acted as the librarian at the Institute of Urban Studies at the University of Winnipeg, where I have assisted many students with their thesis/practicum research. In addition, during 2007-2008 I also taught the department of city planning's required course in thesis/practicum preparation. In both of these capacities I have seen repeated cases of planning students who wish to engage in research that turns out to hinge on an understanding of human spatial behavior, but who were not even aware that such a field existed, to say nothing of the specific theories or methods involved.

In my opinion and experience, EBR constitutes an important substantive component of planning knowledge, but as will be seen below it is neglected both in planning education and in practice.

\subsection{Environmental Psychology and Planning Knowledge}

The integration of EBR into planning knowledge rests on the recognition - developed over the past four decades - that any attempt to construct a more appropriate 
and healthy built environment must proceed from some understanding of the psychological needs of those who will use it and shape it. Stephen Carr, in his seminal article "The City of the Mind" (1970), wrote:

\begin{abstract}
Perceiving and representing the environment, acting in it, and reviewing the consequences are the processes by which we create our personal city of the mind - our own "life space" as it has been called. The form of the environment can help to make that space narrow and confined or broad and open, constantly growing. By organizing our environment properly we can make ordinary city-using tasks simpler to accomplish. We can increase the scope of possible actions for any individual as well as his [sic] sense of competence in carrying them out. And we can increase his [sic] sense of meaning and esthetic pleasure (Carr, 1970, p. 528).
\end{abstract}

EBR researchers have spent decades trying to understand the nature of these human-environment transactions as well as developing ways to put this knowledge to use in a practical way that can benefit human societies. According to Robert Gifford (2007), Environmental Psychology is

the study of transactions between individuals and their physical settings. In these transactions, individuals change the environment and their behavior and experiences are changed by the environment...it includes theory, research and practice aimed at making buildings more humane and improving our relationship with the natural environment (Gifford, 2007, p. 1).

Domains of interest to environmental psychologists include attachment to place (Altman \& Low, 1992); place and self-concept (Twigger-Ross \& Uzzell, 1996); the psychology of home as well as antecedents/effects of homelessness (Rivlin, 1990; Marcus, 2007); the effects of environment on privacy, personal space, territoriality, and crowding (Sommer, 1969; see summary in Gifford, 2007); built environments and crime (Taylor, 2002); the ways in which natural environments can promote health (Kuo, 2001) and community building (Coley, Kuo, \& Sullivan, 1997); environmental perception, cognition, and wayfinding (Downs \& Stea, 1977); effects of natural landscapes (Kaplan \& Kaplan, 1989; Kaplan, Ryan, \& Ryan, 1998); diverse environmental needs across the lifespan and cultures (Gifford, 2007); conservation and sustainable behaviors (Geller, 2002); sacred places (Hester, 1985, 2006); how people cope with and plan for disasters (Peek \& Mileti, 2002); environmental conflict (d'Estree, Dukes, \& Navarrete-Romero, 2002); and how to encourage and nurture public participation in design processes (Sommer, 1983). All of these themes are consistent with planning knowledge.

What is also particularly interesting for our purposes are the very similar disciplinary trajectories between EBR and planning. Both literatures (for example, Beauregard, 1989; Sommer, 1983) reveal that during the 1970s in particular, both planning and EBR researchers began to question or reject their modernist assumptions, positivist epistemologies and comprehensive rationality. Faced with a host of social justice and environmental problems, some planners and psychologists sought to define new parameters for their respective disciplines and to take a more active role outside the academy. Just as architects and planners in the later post-war era realized that an emphasis on formalism was resulting in inhumane built environments, for their part, leaders in what would become known as environmental 
psychology became interested in situating their discipline in real-world settings and in applying their knowledge to solving real-world problems (Sommer, 1983).

Some of the leading writers in EBR also come from city planning backgrounds: Clare Cooper Marcus, who worked as a planner in England and studied City and Regional Planning at Berkeley and has written extensively about the role of the home in the formation of personal identities (Marcus, 2007); Kevin Lynch, who taught city planning at MIT and wrote the seminal "The Image of the City" (1960); Donald Appleyard, an urban designer best known for writing about "Livable Streets" (1981); and Randolph Hester, who teaches urban design at University of California Berkeley and writes about place, meaning, and citizen involvement in planning processes (2006).

Environmental psychologists were also instrumental in institutionalizing that core postmodern planning practice, public participation, in design processes (Dean, 1994 and Chapter 12). Robert Sommer, in particular, promoted "social design":

Social design is working with people rather than for them; involving people in the planning and management of the spaces around them; educating them to use the environment wisely and creatively to achieve a harmonious balance between the social, physical, and natural environment. . . social designers cannot achieve these objectives working by themselves. The goals can be realized only within the structures of larger organizations, which include the people for whom a given project is planned (Sommer, 1983, p. 7).

This connection between people and place-making is key to environmental psychology. As Evans (1996) puts it:

A conceptual topic of continuing interest within environmental psychology is the concept of place. How are places developed, how do they acquire meaning to people, how are they related to people's plans of action, their preferences, and even to their emotional reactions and well being? And what does the concept mean across generations or across cultures? Place making and the development and sustainability of community has been the subject of several recent books in the field (paragraph 21).

Given planning's own strong identification with place-making processes (see Schneekloth \& Shibley, 1995; there are many other examples), the linkages between these disciplines would seem inherent and obvious. Yet, as Lucy (1994) demonstrates, there has long been a gap between planning practice and considerations of human psychology. To address this, Lucy (1994) called upon planners to adopt more interdisciplinary cooperation with other "nourishing" fields. Recent scholarship in planning practice and education also confirms that the legacy of this long-standing disconnect is being reinforced in the academy, where little attention is being paid to EBR in planning pedagogy.

In their examination of knowledge in planning, Ozawa and Seltzer (1999) consulted with planning educators to create a classified list of planning skills and knowledge areas, which was subsequently mailed to over 270 planning practitioners. The list was strongly oriented to competencies, rather than theory. What theory was recorded, again, related to spatial processes in the macroenvironment, with only a general reference to "social forces."

While EBR as such is not referred to in this and other studies in planning knowledge considered for this chapter (e.g., Friedmann, 1996), it was incorporated in 
White and Mayo's (2005) survey of 66 planning educators, which found that not only did educators place a low priority on EBR but it also rated lower in the academic realm than it did in practice.

Of course, the gulf between environmental psychology and all of the design professions - not just planning - has been a continual struggle. In 1973, Donald Appleyard looked at these professional and disciplinary barriers, noting that design professionals may not understand why social science approaches are needed, when only "common sense" is required. They may even see such approaches as a threat to their control over decision-making and the project's financial viability. The "future orientation" of designers is also a barrier to understanding, as psychological research is rarely so. And design professionals often eschew social science research published in psychological journals, which in any case is often "obscurely written" (Appleyard, 1973).

Schneekloth and Shibley (1995) speak of this gap as "fragmentation":

[T] he practice of placemaking is fragmented, and some practices belong to different domains and groups of professionals. There is an ongoing attempt to create boundaries that separate and differentiate the work on many levels revealing a world more concerned with distinction and division than with connection and relationship. Professors and professionals collectively differentiate themselves from "laypeople", even as professors and practitioners seek to differentiate themselves from each other into separate academic and practice domains (Schneekloth \& Shibley, 1995, p. 194).

This is, I submit, the case with city planning and environmental psychology. Commonality of purpose, goals, and means would seem clear. What is needed are ways of crossing disciplinary barriers and translating theories considered outside the domain of planning into forms that can intuitively situate the universality of "beingin-place." I propose that this pedagogical problem may be addressed through the use of hermeneutic film analysis.

\section{4 "Hollywood Hermeneutics" and "Being-in-the-World"}

It bears pointing out that, given their mutual concern with the phenomenology of place, EBR theory and Heidegger's (1962) conception of "Being-in-the-world" or Dasein (literally "there-being") share some basic similarities. For Heidegger, humans are not just self-aware of their own Being, but live purposeful, self-directed lives while interacting with other self-aware Beings. But there is an explicit spatiality to Dasein: the experience of Dasein occurs only as part of a totality within and including the "world." By "world," however, Heidegger is not referring to the physical, objectively measurable Nature all around us, but rather as a function of the process of Dasein's own "world-forming" capacities or the creation of a "complex of reference and relations. . a wholly insubstantial horizon of meaning, a whole of reference in which we always move with so much familiarity that we do not even notice it" (King, 2001, p. 55).

Without going overmuch into the profoundly complex philosophy of Heidegger's formulation of Dasein, ${ }^{2}$ we can see many parallels with the EBR theory. Ittelson, 
Proshansky, Rivlin, and Winkel, (1974), in their early formulation of EBR principles, echo Heidegger when they state that every environment is perceived as unique by each individual. Rapoport (1990), too, has written extensively on the construction of environmental meaning. Furthermore, just as Altman and Rogoff (1987) viewed people and their environments as an indivisible and temporally located totality, so too did Heidegger view Dasein as a single unitary whole:

Self and world belong together in the single entity, the Dasein. Self and world are not two beings, like subject and object. . [instead] self and world are the basic determination of the Dasein itself in the unity of the structure of being-in-the-world (quoted in Guignon, 1993, p. 13).

For the purposes of the analysis to follow, I am concerned with locating in the films and readings insights into this understanding of "Being-in-the-world": how humans make sense of their identities in space, create meaningful "worlds" spatially, and relate to other beings as part of an active human-environment totality.

To undertake such readings, the overall framework for both this chapter and that of the academic assignment on which it reports is that of hermeneutical inquiry. We shall be dealing with the interpretation of "texts" both theoretical and cinematic, and in particular how the interpretation of certain texts informs us in our understanding of other texts. Through this hermeneutic, new insights not possible otherwise create new opportunities for learning. Hermeneutic approaches allow us to recognize these through the discernment of metaphors. Ricoeur (following Aristotle) calls this the discernment of resemblances, or the

rapprochement, the bringing closer together of terms that, previously "remote" suddenly appear "close." Resemblance thus consists in a change of distance in logical space. It is nothing other than this emergence of a new generic kinship between heterogeneous ideas. It is here that the productive imagination comes into play as the schematization of this synthetic operation of bringing closer together (Ricoeur, 1991, p. 9).

We are therefore going to be undertaking hermeneutic readings to "bring closer together" planning theory and EBR and also bringing closer together lived and cinematic understandings of human-environment transactions. Cinema in this case is considered for its power to metaphorically understand the human condition, in the world. In his own search for psychological metaphors, Sullivan (1990) noted that

the world itself and people within it are relational. By this we mean that to know or identify person, things or events, we have to identify or contrast them with other persons, things, or events. In order to come to know and understand something we usually attempt to identify and contrast it with something which we already find familiar (Sullivan, 1990, pp. 1-2).

Motion pictures are, of course, so very familiar they almost constitute a universal language and thus offer a uniquely significant pedagogical platform for engaging with representations of society, and social and power relations:

[T] he growing popularity of film as a compelling mode of communication and form of public pedagogy - a visual technology that functions as a powerful teaching machine that intentionally tries to influence the production of meaning. . suggests how important it has become as a site of cultural politics (Giroux, 2001, p. 587). 
In the view of Giroux, film analysis in the classroom should be "part of a broader circuit of power relations [and] expand the possibilities of multiple readings of texts while making visible how representations work" (p. 53). Activist bell hooks concurs, having found that her students were made more aware of discourses on race, sex, and class through watching films than they had gained from the readings she'd assigned (cited in Giroux, 2001).

Film allows access to an almost endless array of potential "texts" with which to appraise a wide range of human experiences. All films are redolent with such possibilities. As Lau (1991) puts it,

My starting point is to take a film as a text [which] is an inscription of a discourse in which both meaning and intersubjective exchange take place. That is, a text has a double world. As an inscription, the text has a "world of its own" that can be analyzed structurally or semiotically. As a discourse, there is the meaning of an experience being transferred from one sphere of life to another. The text, as a dialectic of the two, can be analyzed not only semiotically for structure but also semantically for meaning that transcends the text itself and points toward a vision of the world (Lau, 1991, p. 4).

What is of interest, then, is what carefully selected intertextual readings Kozlovic's "Hollywood Hermeneutic" (2005) - can tell us about humanenvironment transactions, and thus, as Lau puts it, "transfer meaning from one sphere of life to another" - to enrich planning education and praxis with EBR theory. We are looking at filmed depictions for their ability to illuminate, metaphorically, the human-environment nexus and how best to plan for it.

Before we can undertake such an analysis, however, we will become more acquainted with the theoretical basis for this exercise: the use of film as a window for understanding human spatial behavior.

\section{5 "Begin with the Screen and Move Outward to the City"}

The tenuousness of the line between cinema and reality has long been noted by viewers and film theorists alike. French philosopher Baudrillard (1989), for example, viewed the American cityscape as a screenscape:

Where is the cinema? It is all around you outside, all over the city, that marvelous, continuous performance of films and scenarios...The American city seems to have stepped right out of the movies. To grasp its secret you should not, then, begin with the city and move inward to the screen; you should begin with the screen and move outwards to the city (Baudrillard, 1989, p. 56).

Just as EBR researchers have sought to understand diverse human environmental experiences, so too were early film theorists curious about the psychology of the film-viewing experience. The viewing of projected light in darkened quarters was at the turn of the last century a new form of stimulus and audiences experienced a host of unexpected responses. In his seminal 1916 study of the psychology of film, Munsterberg (1916/1970) reported that audiences were reporting a variety of 
sensory hallucinations and illusions. ...neurasthenic persons are especially inclined to experience touch or temperature or smell or sound impressions from what they see on the screen. The associations become as vivid as realities, because the mind is so completely given up to the moving pictures (Munsterberg, 1970, p. 221).

This immersive empathy is especially relevant when contemplating the narrative and meanings embedded in fictional films. Andrew (1984, p. 45) describes how viewers "are asked to swim in a time stream, and. . cannot look away without the fiction threatening to disappear;" and filmmakers, knowing this, rely "on some substratum of spectator understanding of the type of world that becomes the subject of the film." As a result we are "given over to the world" created by the filmmaker (ibid, p. 44) and the boundaries between our own and that on the screen, for a time, dissolve. This experience is not, of course, categorically the same as awakened consciousness but is more akin to dreaming:

[F]ilm has been compared to the mind...with human perception, dreams or the subconscious...In a sense, film offers us our first experience of an other experience. Thus our understanding of our world can be informed and changed by this other way of experiencing a world, this other view of a similar world (Frampton, 2006, p. 15).

These understandings extend to more, in the view of Kracauer (1968), than just perceiving the world in new ways, but to seeing elements of the world - and our psychological relationship with it - that would otherwise have been hidden from us. "Film renders visible what we did not, or perhaps even could not, see before its advent. It effectively assists us in discovering the material world with its psychophysical correspondences" (Kracauer, 1968, p. 300).

As discussed, environmental psychology is premised on the notion that all of us negotiate meaning in the environment and that no two people will experience the environment in the same way (Ittelson et al., 1974); this corresponds to a major tenet of film studies, which holds that all audiences negotiate meaning in film. As Frampton (2006) observes:

The mix of film and filmgoer is always an original journey - the filmgoer adds the filmind's film-thinking to their own, naturally or subconsciously reconfiguring it in the process...we remake the film via our concepts, and the film remakes our vision (Frampton, 2006, p. 163).

In this way, films do not represent reality, but rather are an interpretation of reality, a creation on the part of the filmmakers, one with which the viewer negotiates meaning. As such this interpretive and creative context represents an extra analytical layer that would otherwise not be available were the students only studying written theory or observing public behavior. Each student - and group of students will interpret a film (and the reading) in different ways, so this makes every film a potentially new learning environment for each session of a theory course.

As we can see, then, there is ample theoretical support for approaching the study of environmental psychology through the use of film. What follows now are some examples of the potentialities this approach affords us. 


\subsection{EBR Theory Goes to the Movies}

Resonances of EBR theories key to understanding "Being-in-the-world" are surprisingly common in the so-called fish-out-of-water movies, where characters familiar with one environment (or time) are thrown into another. This struggle to make sense of and use unfamiliar environments - indeed to establish the nature of reality itself drives the narrative of The Matrix (Silver, 1999), in which we learn that everything we know as reality is in fact a simulation into which we are all "jacked." Neo, a hacker (played by Keanu Reeves), has become aware that there is something "wrong" with his environment and learns that it is actually a simulation. With the help of his mentor, Morpheus (Lawrence Fishburn), Neo is then "born" into the "real world" - which is in fact a burned-out wasteland centuries into a future dominated by machines. However, Morpheus trains Neo to utilize that environment which he once knew as reality in entirely new ways: to move through, act in, and manipulate the environment before becoming "the One" who can be a total master over it.

Throughout the movie, we must be constantly aware of the need to distinguish between reality and illusion. Egon Brunswik's ideas on "probabilistic functionalism" (1947/2001) are highly relevant here, as they suggest that we are always determining from one moment to the next through an interpretation of distal (objective) and proximal (subjective) cues the extent to which our senses are discerning reality. Ittelson (1973) further proposes that our beliefs about the world determine our perceptions: as he puts it, believing is seeing. One can almost hear Lawrence Fishburne's Morpheus when Ittelson (1973, p. 10) writes, "Perception mirrored our innermost values and produced a world which we saw precisely because we wanted to believe in it." But we are urged not to take our perceptions for granted: Carr (1970, p. 518) would have said that Neo, "perhaps sensing that there may be a way to escape [his] bondage. . .begins to ask, 'why?' ".

However, once this question is asked - and the "red pill" taken - Neo begins an irrevocable journey, the course of which is described fairly coherently by Stephen Carr's "phases of man-environment interaction process" (1970, pp. 521-529): Neo first engages in what Carr calls the Directive Phase, in which our needs become such that they direct us to new courses of action

[Neo's] directive phase began with his search for Morpheus. . Although his perception of the information he had gathered up to this point was confusing and almost absurd, Neo attempted to make sense of the environment. . .both as a source of essentials and as a ground for action.

An Intelligence Phase, in which we search for new relevant information from the environment and organize it to be retained:

Neo...follow[s] the "white rabbit" which represented a path to the truth of the Matrix provided by Trinity.

In order for Neo to control his environment, it was crucial for him to first recognize and understand it. [His] preconceived limitation[s] of his "self" then became apparent through his subsequent behaviors. [Once] Neo began to adapt and break down his previous cognitive notions of the physical limitations he was. . . able to "free his mind". 
A Planning Phase, in which appropriate information is retrieved and transformed to be used in the generation, evaluation, and selection of sets of possible action:

Neo struggles with this phase for the majority of the film. He is aware of the concept of the matrix, and what is possible within the alternate environment. It is his ability to "free his mind", and transform his existing models of what is possible within [the real] environment, into what is possible within the matrix environment. From training within the matrix simulators, and retaining new information from first hand experiences, and Morpheus' teachings, Neo was able to plan his use of. . . the matrix.

An Action Phase, in which the plan is executed in a particular environmental context:

This newly acquired information allows Neo to achieve superhuman feats of strength and agility...People who are unaware of such possibilities are unable to accomplish or even comprehend these superhuman actions within the matrix. Neo is able to carry out his superhuman stunts because of his knowledge of the supports and constraints of the computer programmed environment.

Having thus integrated new knowledge - and more importantly, new beliefs about his Being-in-the-world - Neo is capable of formulating and putting into action a plan for rescuing Morpheus after he is captured by Agent Smith (Hugo Weaving).

A Review Phase, in which the effectiveness of the particular course of action is assessed in order to correct further action and to assign value and meaning to the experience:

The meanings and values of reality and existence are drastically shaken over the course of the film. Neo views the matrix upon re-entering for the first time as fake. [Then] Neo sees what he thought of as reality, the matrix environment, for what it truly is [and elements in the] environment gain new meanings. Telephones don't exist as a simple communication device anymore; they are...critical points of exit and entry into the matrix environment. As Neo ventures through Stephen Carr's five phases. . .he is able to comprehend the matrix environment for what it truly is. As a result, he is "enlightened" at the climax of the film, becoming "the One", an unstoppable entity manipulating the matrix.. however he sees fit, rendering him invincible within the simulated reality.

What we see in The Matrix is that, whether we live within an environment with which we are quite familiar or must adjust to a radically new one, we are continually engaging in these transactional phases, with the ultimate goal of seeking environmental meaning. And, like the film itself, these meanings can take religious or quasi-religious forms.

Traditionally, humans have sought for supernatural explanations for their spatial transactions. Such cultures, according to religious historian Mircea Eliade, believed that "space is not homogenous; [they] experienc[e] interruptions, breaks in it; some parts of space are qualitatively different from others" (1959, p. 20). These spaces are considered sacred.

Sacred space acts as a wayfinding tool while also providing an element of mystery, adding interest to every day life. For religious man, these sacred spaces are shared with a likeminded group of people, forming a community (ibid, p. 2). 
In our more rationalist era, we are less disposed to find this meaning in God or gods, and our urban settings are replete with "homogenous," "neutral," and profane environments. However, as Eliade explains (1959), our contemporary spatial experiences are nonetheless "crypto-religious" in nature - that is, responses to

...privileged spaces, qualitatively different from all others - a man's birthplace, or the scenes of his first love, or certain places in the first foreign city he visited in youth. Even for the most frankly non-religious, all these places still retain an exceptional, a unique quality; they are the "holy places" of his private universe, as if it were in such spots that he had received the revelation of a reality other than that in which he participates in his ordinary daily life (Eliade, 1959, p. 24).

Such spatial behaviors dominate Falling Down (Harris, Kopelson, Weingrod, \& Schumacher, 1993). Michael Douglas' character William Foster, a laid-off defense worker, is estranged from his wife and daughter and stuck in traffic on his way to his daughter's birthday party. As the heat and his existential frustrations boil over, he abandons his car and embarks on a pilgrimage across a profane and brutal Los Angeles, one in which his personal cosmogony (Eliade, 1959) crashes up against contemporary America. Calling himself D-FENS (after his license plate), Foster makes his way across a landscape of "chaos" - a profane world - in which there is no moral center and no myths, only nonsensical "rules." As one film reviewer put it,

The deterioration of American society is in evidence everywhere. From the decaying buildings and lousy service, to the liars and cheats who panhandle rather than work - everywhere Foster goes, he's confronted by the rot, the anarchy, the spiritual malaise (Russell, 1999, paragraph 12).

The only place that matters to D-FENS is his former home, where his estranged wife and daughter live. This is his axis mundi or "center of the world," what Eliade would call the "holy place of his private universe". To reach it Foster is willing to violate any number of privileged places along the way - places that others have made "sacred" in a crypto-religious fashion (a gang and their hillside, a neo-nazi and his shrine to fascism, elderly duffers and their golf course). What drives his pilgrimage is not just his longing for his axis mundi but his feelings of betrayal against an America that he no longer recognizes.

William Foster's ideal America is to him what a cosmogony is to sacred man. A cosmogony is an account of the creation of the world, or a set of ideal beliefs. William Foster has... essentially been cast from the paradise ideal of his American dream. Just like Satan in the Christian cosmogony had been cast from heaven to the profane environs of Hell, so has William Foster been cast into the profane environment of south-central Los Angeles. . . [And just as] Satan function[s] in the Christian cosmogony... as punishment for those sinning against what is ideal within the Christian cosmogony, William Foster punishe[s] those who sinned against his individual cosmogony.

There are hints throughout the film as to William Foster's ideas of the perfect life, which is what can be further defined as the American dream. The American dream to William Foster appears to be the ideals from the 1950's through to the 60's; a nice loving family, a house with a yard, a steady nine to five job, a booming economy that encourages low market prices, predominantly white citizens and a general attitude of respect amongst everyone. 
This "cosmogony" is, of course, hardly confined to disgruntled film characters, but key elements within it underlie the presumptive conservative metanarrative driving a huge range of public policy debates, from immigration to day care to welfare. Just as D-FENS rails against immigrant shopkeepers and gang members for having changed his country, so too are our spatial interrelations becoming ever more problematized by polarizing and fearful discourses on immigration, which portray newcomers as a threat (Sandercock, 2003). Distrust and animosities born of prejudices are surely to follow.

These forces are portrayed to devastating effect in the Paul Haggis film Crash (Cheadle, Haggis, Moresco, Schulman, \& Yari 2004), which peels back the layers of a society steeped in racism - but subtly shows how this pathology is exacerbated by the built environment. The characters in the film are often sealed in their cars or their respective nodes of wealth and poverty - and as a consequence are unable to engage in the kinds of casual interactions necessary for a functioning society.

Dispersed, relatively isolated [urban] nodes create physical distance... which in turn
demands the necessity for constant [commuting] throughout the city. Vectors, which serve
as the links between these nodes are usually dominated by private transportation (Phillips
and Smith 2004). As [automobiles are] essentially private nodes within public vectors - a
"home on the road" (Fraine et al., 2007) - an ambiguity of spatial usage materializes.
The automobile then becomes an extension of the skin and insulates the senses from
environmental details and stimuli. This desensitization does not only exist between man
and environment, but also among city dwellers. As [Don Cheadle's character, Detective
Graham Waters] says, "it's the sense of touch ... in a real city, you walk, you brush past
people, people bump into you. In L.A. nobody touches you. People are always behind this
metal and glass, I think we miss that touch so much that we crash into each other just so we
can feel something."

Research into such negotiation of interpersonal space as a form of nonverbal communication can tell us a lot about what we seen in the film. Edward Hall's early work in intercultural spatial relations (1966) explored how Anglo-American standards and expectations concerning personal space and crowding (i.e., in a "noncontact" culture) were pronouncedly different from people from "contact" cultures. Research since then has shown strong confirmation of his observations not just for broad national groups, but for urban subcultures as well. Studies have shown, for instance, that Mexican-Americans maintain much closer interpersonal distances than do Anglo-Americans or Afro-Americans (summarized in Aiello \& Thompson, 1990). Findings such as these suggest that miscommunication between such groups is quite likely in ever more multiethnic, multicultural countries:

Different perceptions of space may often lead to different definitions of what constitutes an inappropriate interaction distance. . .consequently miscommunication can occur when individuals from different cultures attempt to interpret each other's spatial behavior (Aiello \& Thompson, 1990, p. 109).

A key element of such miscommunication relates to attribution/expectancy, or what people assume strangers will do, which in intercultural contexts can often be based on stereotypical assumptions (Burgoon \& Hubbard, 2004). We see this throughout the film: Jean Cabot (Sandra Bullock), upon seeing two black youths 
approaching her and her husband (Brendan Fraser), reacts visibly and fearfully; she later distrusts Daniel Ruiz, the Latino locksmith (Michael Pena), as does Iranian shopkeeper Farad (Shaun Toub); Officer Hansen (Ryan Phillipe) picks up Peter Waters (who is black) in his car and, believing (mistakenly) that Waters has a concealed weapon, shoots him.

The personal space implications peculiar to L.A. were also not lost on at least one of the film's actors. In preparing for the film, Ryan Phillipe told reporters,

When I first moved to L.A. from the East, I thought it was the strangest place on Earth because people didn't interact and mix the way they do in New York and Philly where I spent my youth... There is something oddly segregated about L.A., even though it is the most liberal, leftist, flaky, New Agey, forward-thinking city in the U.S. [Los Angelinos] cling to their personal space. They protect their personal space like nowhere I've seen in this country (Hobson, 2005).

When groups of varying socioeconomic capacities are spatially segregated or ghettoized, and when public spaces capable of encouraging social mixing are not available, people of diverse cultures and ethnicities will only encounter the "other" in unusual circumstances rather than in everyday encounters (Leadbeater, n.d.). Unfortunately, the interactions most of the characters in the movie do have are profoundly racist and what Phillips and Smith (2006) would call "uncivil."

Urban incivilities, prejudice, and hostility toward immigrant "Others" are no longer strictly interpersonal but have become practically institutionalized in the twenty-first century London in Children of Men (Abraham et al., 2006). In the year 2027, humanity is decades away from extinction. No babies have been born for 18 years, and civilization is undergoing slow collapse.

[The London of 2027 is] a chaotic, dense [and] polluted metropolis where the government instills fear in the general public and exercises force to rid the country of its problematic illegal immigrant population in an almost Naziesque manner. Police rampage through apartment buildings that house foreigners and rob, beat, deport or kill any immigrants they may capture; armed guards restrict refugee access into Britain and control them by any means possible, while the Government is responsible for a series of planned bombings... posed as terrorist attacks.

Sustainable design is non-existent because people don't care about the future of the world anymore. Everyone seems obsessed in finding out why there is infertility not at trying to [heal nature], which could be the formal cause of the disaster.

The global psychic trauma of the certainty of extinction has rendered purposeless almost all human activity. Yet, as Macy (1995) would argue, this is hardly the stuff of science fiction:

Until the late twentieth century, every generation throughout history lived with the tacit certainty that there would be generations to follow. Each assumed without questioning that its children and children's children would walk the same Earth, under the same sky. Hardships, failures and personal death were encompassed in that vaster assurance of continuity. That certainty is now lost to us, whatever our politics. That loss, unmeasured and immeasurable, is the pivotal psychological reality of our time (Macy, 1995, p. 240).

It is also of course the pivotal psychological reality of the main characters in the film. Years ago, Theo (Clive Owen) and his wife Julian (Juliana Moore) lost 
their son in a pandemic, and the grief ended their marriage; now universal sterility and accompanying grief are tearing apart civilization. People try to carry on but the futility is so open that the government has issued suicide kits called "Quietus."

In Macy's (1995) view, our repressed grief and terror are holding us back from taking action; for Theo - like most everyone else in the film - this repression and accompanying psychological numbness are the only ways he can carry on.

Upon the loss of his son Theo transitioned from someone who lived a largely empowered life... to someone who led a double life and lived constantly in [what Macy calls the] "fear of pain."

Theo is held captive by many fears [and has] many numbing devices [e.g., alcohol] that he uses as a response to his fears... He continues to live his life as if nothing has changed. He goes to work and continues to live in his apartment using these numbing devices to deal with the pain and fear that he feels. The energy that his repression is taking out of him is making him unable to feel any emotion.

Like many of us, Theo is suffering from what Macy (1995) calls environmental despair. But - and consistent with the EBR theory concerning the restorative capacities of natural settings (Kaplan, 1995) - the extent to which Theo experiences such despair is sensitive to his exposure to natural settings:

When in the... controlled... built environments of London... Theo [is] extremely introverted, impersonal and rude as he is only concerned for his own personal well-being and safety. When placed into the comfort of [his friend Jasper's cottage in the forest] we are shown the side of Theo that allows us to believe he was once capable of being someone who stood up for that which he believed in and having a family, which he loved and in return loved him. It is this environment that we are shown the truest representation of who Theo was, is and can be as a person.

It is not until Theo is abducted by the underground rebel group, the Fishes, and hired to escort a young pregnant woman named Kee (Clare-Hope Ashitey) to the secretive Human Project that Theo becomes engaged and is able to act. What has happened to him? Theo breaks out of this trance when he realizes that Kee is pregnant - and he experiences what Macy (1995) calls a catharsis:

... his repressed emotions are all refocused on getting in and out of Bexhill to the Human Project ship alive. He has meaning and purpose in his life again and he no longer simply moves through the environments he encounters along the way, but thinks about and reacts to them to ensure survival.

Slowly throughout the movie as Theo helps finish the task he has been charged with we are able to witness his personal transformation from a person suffering from "environmental despair" and a loss of "empowerment" back into someone who is. . becoming empowered again and standing up for what it is he believes in.

He becomes "empowered with" (Macy, 1995) Kee - and by extension, the rest of humanity - and realizes that the fate of his species rests with him. He escapes with Kee and they make their way to the coast. He delivers her baby in the most horrible of conditions and leads her through a hellish battle scene - becoming fatally wounded in the process - but is still sufficiently "empowered with" her to coach her in parenting, and as he dies takes joy in seeing her rock her baby as he cared for his own lost boy. 
Theo's sacrifice of himself, when [he] essentially puts the good of humanity ahead of his own, demonstrates [the] interconnectedness of all people.

That Theo breaks through his despair and is "empowered with" others shows us that hope is not some thoughtlessly optimistic state of mind but rather the result of honestly facing one's own grief and recognizing our interconnections with others.

\subsection{Discussion}

It has been tempting in the classroom setting to remark on the very close associations between the chosen films and readings, almost to the extent that it is hard to imagine how the filmmakers could have made these films without having read - or become familiar with - the theories in question. Needless to say, such familiarity on the part of the filmmakers is quite unnecessary. Instead what we see in these intersections is surely an indication of the universality of the human experience expressed in diverse ways. As Geoffrey Hill shows in his Illuminating Shadows: The Mythic Power of Film, the films he examines "are largely mythicized at the subconscious level. While [filmmakers] might not be aware of their mythic participation, they nonetheless convey significant mythic import" (Hill, 1992, p. 17). Through this engagement with myth, we are faced at a very fundamental level with the complexities of the human experience and with new understandings of spatial power relations.

We can see how the EBR theory may be very effectively illustrated through film analyses. What is more significant though is how these readings can also challenge existing social structures and can therefore be radicalizing. Giroux (2001, p. 589) concurs:

[M]any students see in the public issues addressed by film culture a connection to public life that revitalizes their sense of agency and resonates with this sense of the importance of the cultural terrain as both an important source of knowledge and of critical dialogue.

Critical dialog and the knowledge that results are essential to engaging contemporary crises. We all have the potential to enrich our collective experience of Heidegger's Dasein, but only if we, as Carr (1970) suggests, ask "why"? Questioning and challenging what we assume to be immutable realities are the beginning of liberation.

Such interrogations of existing structures must begin with a reflexive posture, to question the role of the designer in society, and motion pictures were especially useful for starting this conversation in the classroom. Oftentimes - as in Falling Down and Crash - we see how the choices made by design professionals as a part of the political economy of real estate have resulted in dehumanizing, alienating urbanism. Other times, blatantly oppressive settings (like the prison camp in Children of Men) are presumed to have had designers, who knew exactly what these places would be used for.

A most compelling example of this latter portrait is the science fiction/horror film Cube (Meh \& Natali, 1997). Five strangers awaken in a six-sided room, with a 
hatch on each wall, floor, and ceiling. They realize that each hatch leads to an almost identical room - identical save for the color and the fact that some might be lethally booby-trapped. One of the characters, Worth (played by David Hewlett), is revealed to have been an architect who worked on the design of the vast structure. He says that it was a top-secret military project - a prison - and that his role in the project as a designer was very minor and compartmentalized: all he was required to do was come up with the exterior parameters.

What the film suggests about environmental design is both subversive and disturbing: that oppression must be spatially situated, requiring as it does a particular stage that must be envisioned, designed, and built according to the specifications of a dominant power. The prison of The Matrix may have been virtual, but it is no less a designed environment than that of Bexhill in Children of Men or the Cube. That Worth didn't know the ultimate purpose of the project does not relieve him of his share of responsibility he holds for the violence that follows.

The students in the Theory of Design 3 course were eager to engage with these (and other) ethical dilemmas and the film seminars often revolved around direct questions to fellow students about what decisions they would make or what role they felt designers needed to take to change present conditions, injustices, and crises. This reflexiveness was particularly poignant in one of the reflections on Children of Men:

What's most startling about the movie is that [the people in the film] who did not react in time to prevent [their] crisis are the people of today. The film is set in the year 2027, Theo is maybe in his late $30 \mathrm{~s}$ to mid $40 \mathrm{~s}$ - the age range our classmates [will be] in that year.

These students were aware of their own vulnerability to what Macy (1995) calls the "fears that hold us captive":

Each fear is directly related to a set of thought patterns that... can be directly attributed to their stance and action, or lack of, regarding environmental issues. "Fear of Causing Pain"... relates to our desire... to bring as little trouble and worry possible upon those we care for. The "Fear of Appearing Stupid" stems from... not [wanting] to complain about a problem that we are unable to provide an immediate solution for in fear of being called out by our peers as nothing more than a whining bleeding heart environmentalist with no real solutions to our stated problems. The "Fear of Feeling Powerless" is the most realistic and commonly experienced of the bunch that is presented. Many people do not like to feel as if they have no control over the situation in which they are in as this feeling of helplessness is contradictory to the environmental responses of control and safety that have been programmed into us over time. The problem with this however is that this helplessness is the largest problem [related to] "environmental despair," as many people have taken the stance of "I don't think about that because there is nothing I can do about it." The perception held in this fear is that which is most in need of change in order for us as a society to break through this "Environmental Despair" and begin to exact positive change on the whole.

The films and readings sampled in this chapter played a formative role in engaging students in a critical discussion about environments, users, and designers and in challenging assumptions about all of them so as to be better able to participate in bringing about these positive changes. 


\subsection{Conclusions}

More than three decades have passed since Appleyard's (1973) call for more integration between the social sciences and design professions. Yet we see that there are still significant gaps between planning and environmental psychology - gaps in understandings that, if mended, could contribute to making more humane places. I propose that the place to start is in planning education, which continues to be focused on macro socio-spatial processes to the detriment of understanding more intimate human-environment transactions.

I suggest that an engaging and illuminating way to address this gap is through the integration of hermeneutic film readings into planning education, concentrating on readings of environmental psychology theories in cinema. The hermeneutical interpretations gleaned from such a synthesis can enrich planning discourse and provide the basis for more interdisciplinary approaches.

What do we stand to gain?

Instead of talking in general terms about "planning with" publics, planners need to understand first of all how people engage with their environments. These are fundamentally individual psychological processes that, while they can be experienced collectively, cannot be fully studied at a macro level. The interpretations above, however, shed some light on the "world forming" (Heidegger, 1962) in which we all engage. Neo in The Matrix is deeply involved in learning about, interpreting and furthermore shaping his environment, and his ability to question his assumptions about his environmental transactions is the foundation for his evolution.

Instead of talking in general terms about "place-making" and "encouraging a sense of place" planners need to understand the processes by which places acquire meaning for people. Places are the foundation for our sense of self, our identity, our "Being-in-the-world". Our preferences and love for certain places may be rooted in conceptions of the sacred or in more crypto-religious terms, as we see in Falling Down. Regardless, our beliefs - our personal cosmogonies - about ourselves in space are also situated in widely held ideologies that contribute to social and power relations.

If planners are going to be able to understand - and hopefully transform - these relations, then they need a better sense of the psychological dimensions of our socio-spatial relations. Our interpersonal relations are always spatially situated and subject to the dynamic interplay of our collective efforts to negotiate interpersonal distances, territoriality, and privacy (Altman, 1975). The incivilities in Crash show us that, when denied the opportunity to actually carry out these functions with one another in space, people retreat into physical and psychological enclaves that only deepen already entrenched racial and class divides.

Such social and economic inequities are but one of many of the seemingly intractable challenges planners face, along with urban sprawl, climate change, environmental degradation, and energy depletion. Portents of dystopic futures surround our work and can make our efforts seem insignificant to the task at hand. If we are to have confidence that our interventions can make a difference and to continue engaging in these efforts, then planners need to move beyond simplistic notions of hope, optimism - or worse, despair and futility. We need to attain and maintain the 
strength to question and transform our present spatial arrangements. To do so, we must - like Theo in Children of Men - learn to move beyond despair (Macy, 1995) and be "empowered with" our fellow citizens, nonhuman species, and habitats.

The immediacy and immersive nature of cinema provides us with a window into these and other potentialities. When matched thoughtfully with relevant environmental psychology theory, motion pictures can offer the planning student an incredibly rich learning environment. These are but a few examples: thousands of possible film/reading combinations and interpretations are out there that can yield even more profound insights for planning scholarship, education, and practice.

Acknowledgements I thank the Environmental Design Program at the University of Manitoba for its cooperation with this project, especially the program's Chair, Associate Professor Eduard Epp. As well, thanks are owed to Dr. Jino Distasio, Director of the Institute of Urban Studies at the University of Winnipeg, for his support in the preparation of this chapter. Thanks as well to my Teaching Assistant Jennifer Lim. Finally and most significantly, I am especially indebted to the students from the 2008 class of students of EVDS 2610, Theory of Design 3 at the Environmental Design program at the University of Manitoba. Your enthusiasm for the project - and the course was most gratifying. I thank the following students in particular for allowing me to incorporate some of their eloquent insights, observations and ideas into this chapter: Miranda Adam, David Burns, Michael Chan, Billy Chung, Matt Cibinel, Tom Fougere, James Frank, Ashley Laing, Kaley Lawrence, Darci Madlung, Bret Mack, Mumtaz Mirza, Phan Tu Ngoc, Devin Segal, Aiden Stothers, Nils Vik, Zephyra Vun, and Taren Wan. Thank you so much for all of your contributions!

\section{Notes}

1. The preferred term in this paper.

2. A fuller explication of Dasein is far beyond the scope of this paper. For excellent introductions to these ideas, see Guignon (1993), King (2001), and Mulhall (2005).

\section{Films Discussed in this Paper}

Abraham, M., Newman, E., Smith, I., Shor, H., Smith, T., Bliss, T. A., Bernstein, A. (Producers), \& Cuarón, A. (Director). (2006). Children of men. [Motion Picture]. United States: Universal Pictures.

Cheadle, D., Haggis, P., Moresco, R., Schulman, C., Yari, B. (Producers), \& Haggis, P. (Director) (2004). Crash [Motion Picture]. United States: Lions Gate Films.

Harris, T., Kopelson, A., Weingrod, H. (Producers), \& Schumacher, J. (Director). (1993). Falling down [Motion Picture]. United States: Warner Brothers.

Meh, M. (Producer), \& Natali, V. (Director). (1997). Cube [Motion Picture] Canada: CineplexOdeon Films.

Silver, J. (Producer), Wachowski, A., \& Wachowski, L. (Writers/Directors). (1999). The matrix [Motion Picture] United States: Warner Brothers.

\section{References}

Aiello, J., \& Thompson, D. (1990). Personal space, crowding and spatial behavior in a cultural context. In I. Altman, A. Rapoport, \& J. F. Wohlwill (Eds.), Environment and culture. Environment and behavior (Vol. 4). New York: Plenum Press.

Altman, I. (1975). The environment and social behaviour: Privacy, personal space, territoriality and crowding. Monterey CA: Brooks/Cole. 
Altman, I., \& Low, S. M. (1992). Place attachment. New York: Plenum Press.

Altman, I., \& Rogoff, B. (1987). World views in psychology: Trait, organismic and transactional approaches. In D. Stokols, \& I. Altman (Eds.), The handbook of environmental psychology (Vol. 1). New York: Wiley.

Andrew, D. (1984). Concepts in film theory. New York: Oxford University Press.

Appleyard, D. (1973). Environmental planning and social science: Strategies for environmental decision making. Institute of Urban and Regional Development, University of California, Berkeley, CA, Working Paper issue: 1973, 217.

Appleyard, D. (1981). Livable streets. Berkeley, CA: University of California Press.

Baudrillard, J. (1989). America. C. Turner (trans). New York: Verso.

Beauregard, R. A. (1989). Between modernity and postmodernity: The ambiguous position of US Planning. Environment and Planning D: Society and Space, 7, 381-395.

Brunswik, E. (2001). The essential brunswik: Beginnings, explications, applications. K. R. Hammond \& T. R. Stewart (Eds.). New York: Oxford University Press.

Burgoon, J., \& Hubbard, A. S. E. (2004). Cross-cultural and intercultural applications of Expectancy Violations Theory and Interactions Adaptation Theory. In W. B. Gudykunst (Ed.), Theorizing about intercultural communication. Thousand Oaks, CA: Sage Publications.

Carr, S. (1970). The city of the mind. In H. Proshansky, W. H. Ittelson, \& L. G. Rivlin (Eds.), Environmental psychology: Man and his physical setting. New York: Holt, Rinehart \& Winston.

Coley, R. L., Kuo, F. E., \& Sullivan, W. C. (1997). Where does community grow? Environment and Behavior n, 29, 468-494.

Dean, A. (1994). Socially motivated architecture. In W. Lillyman, M. F. Moriarty, \& D. J. Neuman (Eds.), Critical architecture and contemporary culture. New York: Oxford University Press.

D’Estree, T. P., Dukes, E. F., \& Navarrete-Romero, J. (2002). Environmental conflict and its resolution. In R. Bechtel, \& A. Churchman (Eds.). The handbook of environmental psychology (2nd ed.). New York: John Wiley \& Sons.

Downs, R. M., \& Stea, D. (1977). Maps in minds: Reflections on cognitive mapping. New York: Harper \& Row.

Eliade, M. (1959). The sacred and the profane: The nature of religion. New York: Harper \& Row.

Evans, G. (1996). Environmental psychology as a field within psychology. Retrieved July 13, 2008, from http://www.ucm.es/info/Psyap/iaap/evans.htm

Frampton, D. (2006). Filmosophy. London: Wallflower Press.

Fraine, G., Smith, S., Zinkiewics, L., Chapman, R., \& Sheehan, M. (2007). At home on the road? Can drivers' relationships with their cars be associated with territoriality? Journal of Environmental Psychology, 27, 204-214.

Friedmann, J. (1996). The core curriculum in planning revisited. Journal of Planning Education and Research, 15, 89-104.

Geller, E. S. (2002). The challenge of increasing proenvironmental behavior. In R. Bechtel \& A. Churchman (Eds.), Handbook of environmental psychology (2nd ed.). New York: JohnWiley \& Sons.

Gifford, R. (2007). Environmental psychology: Principles and practice (4th ed.). Colville, WA: Optimal Books.

Giroux, H. (2001). Breaking into the movies: Pedagogy and the politics of film. JAC: A Journal of Composition Theory, 21, 583-98.

Guignon, C. B. (1993). Cambridge companion to Heidegger. Cambridge: Cambridge University Press.

Hall, E. (1966). The hidden dimension. Garden City, NY: Doubleday.

Heidegger, M. (1962). Being and Time. J Macquarrie, E Robinson (trans.). New York: Harper and Row.

Hester, R. (1985). Subconscious landscapes of the heart. Places, 2(3), 10-22.

Hester, R. (2006). Design for ecological democracy. Cambridge, MA: MIT Press.

Hill, G. (1992). Illuminating shadows: The mythic power of film. Boston: Shambhala. 
Hobson, L. (2005). Matt, Ryan team up as L.A. Cops. The Calgari sun, May 1st 2005. Retrieved April 8, 2008, from http://r-phillippe.com/calgarysun2005.php

Ittelson, W. H. (1973). Environment, perception, and contemporary perceptual theory. In W. Ittelson (Ed.), Environment and cognition. New York: Seminar Press.

Ittelson, W., Proshansky, H., Rivlin, L., \& Winkel, G. (1974). An introduction to environmental psychology. New York: Holt, Rinehart \& Winston, Inc.

Kaplan, S. (1995). The restorative benefits of nature: Toward an integrative framework. Journal of Environmental Psychology, 15, 169-182.

Kaplan, R., \& Kaplan, S. (1989). The experience of nature: A psychological perspective. New York: Cambridge University Press.

Kaplan, R., Ryan, R., \& Kaplan, S. (1998). With people in mind: Design and management of everyday nature. Washington: Island Press.

King, M. (2001). A guide to Heidegger's being and time. Albany: State University of New York Press.

Kozlovic, A. K. (2005). Hollywood hermeneutics: A religion-and-film genre for the 21st century. Film Journal, 11. Retrieved March 26, 2008, from http://www.thefilmjournal.com/ issue11/religion.html

Kracauer, S. (1968). Theory of film: The redemption of physical reality. London: Oxford University Press.

Kuo, F. (2001). Environment and crime in the inner city: Does vegetation reduce crime? Environment and Behavior n, 33(3), 343-367.

Lau, J. K. W. (1991). "Judou": A hermeneutical reading of cross-cultural cinema. Film Quarterly, $45,2-10$.

Leadbeater, C. (n.d.). Remixing cities. CEOs for cities, Chicago. Retrieved April 24, 2008, from http://www.ceosforcities.org/rethink/research/files/RemixingCities.pdf AU

Lucy, W. (1994). If planning includes too much, maybe it should include more. Journal of the American Planning Association, 60, 305-318.

Lynch, K. (1960). The image of the city. Cambridge: MIT Press.

Macy, J. (1995). Working through environmental despair. In T. Roszak, M. E. Gomes, \& A. D. Kanner (Eds.), Ecopsychology: Restoring the earth, healing the mind. San Francisco: Sierra Club.

Manzo, L. C., \& Perkins, D. (2006). Finding common ground: The importance of place attachment to community participation and planning. Journal of Planning Literature, 20, 335-350.

Marcus, C. C. (2007). House as a mirror of self. Newburyport, MA: Red Wheel.

Mulhall, S. (Ed.). (2005). Routledge philosophy guidebook to heidegger and being and time. London: Routledge.

Munsterberg, H. (1916/1970). The photoplay: A psychological study. New York: Arno Press \& The New York Times.

Ozawa, P., \& Seltze,r E. (1999). Taking our bearings: Mapping a relationship among planning practice, theory and education. Journal of Planning Education and Research, 18, 257-266.

Phillips, T., \& Smith, P. (2006). Rethinking urban incivility research: Strangers, bodies and circulations. Urban Studies, 43, 879-901.

Peek, L. A., \& Mileti, D. S. (2002). The history and future of disaster research. In R. Bechtel \& A. Churchman (Eds.), Handbook of environmental psychology (2nd ed.). New York: JohnWiley \& Sons.

Rapoport, A. (1990). The meaning of the built environment: A nonverbal communication approach. Tucson: University of Arizona Press.

Ricoeur, P. (1991). From text to action: Essays in Hermeneutics, II (K. Blamey \& J. B. Thompson, Trans.). Evanston, Il: Northwestern University Press.

Rivlin, L. G. (1990). The significance of home and homelessness. Marriage and Family Review, 15, 39-56.

Russell, L. (1999). Falling down. Filmcourt. Retrieved April 23, 2008, from http://www. culturecourt.com/F/Hollywood/FallDown.htm 
Sandercock, L. (2003). Cosmopolis II: Mongrel cities in the 21st century. London: Continuum.

Schneekloth, L. H., \& Shibley, R. G. (1995). Placemaking: The art and practice of building communities. New York: Wiley.

Sommer, R. (1969). Personal space: The behavioral basis of design. New York: Prentice Hall.

Sommer, R. (1983). Social design: Creating buildings with people in mind. Eaglewood Cliffs, NJ: Prentice-Hall.

Sullivan, E. (1990). Critical psychology and pedagogy: Interpretation of the personal world. Toronto: The Ontario Institute for the Study of Education Press.

Taylor, R. (2002). Crime prevention through environmental design (CPTED): Yes, no, maybe, unknowable, and all of the above. In R. Bechtel, \& A. Churchman (Eds.), Handbook of environmental psychology. New York: John Wiley \& Sons.

Twigger-Ross, C. L., \& Uzzell, D. L. (1996). Place and identity processes. Journal of Environmental Psychology, 16, 205-220.

White, S. S., \& Mayo, J. M. (2005). Environmental education in graduate professional degrees: The case of urban planning. The Journal of Environmental Education, 36, 31-38.

Whyte, W. H. (1988). City: Rediscovering the center. New York: Doubleday. 